\title{
Public health advocacy in action: the case of unproven breast cancer screening in Australia
}

\section{Rebecca S Johnsona, Emma J Croager, ${ }^{\mathrm{b}, \mathrm{c}}$, Caitlin B Kameron ${ }^{\mathrm{b}, \mathrm{e}}$, Iain S Prattb,c, Thomas D Vreugdenburg ${ }^{\mathrm{d}}$ and Terry Slevinin}

a Telethon Type 1 Diabetes Family Centre, Perth, Western Australia

b Cancer Council Western Australia, Perth

cWA Cancer Prevention Research Unit, Curtin University, Perth, Australia

'School of Population Health, University of Adelaide, South Australia

e Corresponding author: ckameron@cancerwa.asn.au

\section{Article history}

Publication date: September 2016 Citation: Johnson RS, Croager EJ, Kameron CB, Pratt IS, Vreugdenburg TD, Slevin T. Public health advocacy in action: the case of unproven breast cancer screening in Australia. Public Health Res Pract. 2016;26(4):e2641648. doi: http:// dx.doi.org/10.17061/phrp2641648

\section{Key points}

- Thermography, electrical impedance scanning and elastography are nonmammographic devices that have been promoted directly to consumers for breast cancer screening, despite a lack of evidence of efficacy

- Cancer Council Western Australia undertook strategic research, used media and policy advocacy, and engaged with the Australian Competition and Consumer Commission to investigate this issue

- In 2014, two breast imaging companies were found by the Federal Court of Australia to have engaged in misleading and deceptive conduct

\section{Abstract}

In recent years, nonmammographic breast imaging devices, such as thermography, electrical impedance scanning and elastography, have been promoted directly to consumers, which has captured the attention of governments, researchers and health organisations. These devices are not supported by evidence and risk undermining existing mammographic breast cancer screening services.

During a 5-year period, Cancer Council Western Australia (CCWA) used strategic research combined with legal, policy and media advocacy to contest claims that these devices were proven alternatives to mammography for breast cancer screening. The campaign was successful because it had input from people with public health, academic, clinical and legal backgrounds, and took advantage of existing legal and regulatory avenues.

CCWA's experience provides a useful advocacy model for public health practitioners who are concerned about unsafe consumer products, unproven medical devices, and misleading health information and advertising.

\section{Introduction}

The promotion of emerging breast cancer imaging devices directly to consumers has generated increasing interest and concern internationally. ${ }^{1-3}$ In 2010, Cancer Council Western Australia (CCWA) became aware of several commercial breast imaging companies in Perth, Western Australia, that were offering nonmammographic 'screening'. CCWA identified at least three classes of devices being promoted: thermography, electrical impedance scanning and elastography.

There is a paucity of scientific evidence supporting the efficacy of these devices for breast cancer screening ${ }^{4}$; however, if they are promoted directly 
to women, they may be perceived as an alternative to mammography, and women might choose these companies and devices instead. ${ }^{5}$ At an individual level, women who are persuaded by misleading claims cannot give fully informed consent, are subject to ineffective tests and, if a lesion exists, risk a delayed breast cancer diagnosis. False positive and false negative results have considerable negative psychological and practical consequences for many women.

At a population level, the unregulated growth of alternative breast imaging services may cause confusion, and undermine consumer confidence and participation in publicly funded breast cancer screening programs, such as BreastScreen WA. There is also a clear potential for these companies to increase the burden on the healthcare system by referring women for unnecessary further investigations.

CCWA is Western Australia's biggest cancer charity. Its mission is to "work with [the] community to reduce the incidence and the impact of cancer", with a commitment to making a real difference. ${ }^{6}$ Specifically, this includes advocating for and supporting existing publicly funded, evidence based programs such as BreastScreen and the National Bowel Cancer Screening Program. ${ }^{7}$ CCWA works closely with these and other like-minded agencies to improve participation by the target group in appropriate screening.

This paper looks back at each step in a series of advocacy activities led by CCWA, which culminated in a successful outcome and were intended to protect the public from the potential harms associated with unproven breast imaging. It was not planned as a campaign; however, it had several of the characteristics of a comprehensive advocacy campaign.

\section{Gathering the evidence}

The initial stage of the project investigated the level and quality of evidence surrounding the devices. The National Health and Medical Research Council found "no evidence of sufficient quality to demonstrate thermography is effective for early detection or screening for breast cancer". ${ }^{8}$ This position is supported by recent systematic reviews of the literature on thermography, electrical impedance scanning and elastography, which found that there was not sufficient evidence to support their use for breast cancer screening or diagnosis. 4,9,10 CCWA developed a consumer fact sheet on the evidence that was published on its website in 2010. ${ }^{11}$

CCWA then collaborated with BreastScreen WA and The University of Western Australia to produce a report on companies providing unproven breast imaging services in Western Australia. ${ }^{12}$ By March 2011, there were at least 28 companies across Australia offering unproven breast imaging services, including in rural areas that may not have regular or immediate access to mammographic breast screening. ${ }^{13}$
In light of the paucity of evidence and the wide distribution of the companies, CCWA and Curtin University conducted intercept surveys with 300 women aged 25-54 (representing the target market) to assess the impact of breast imaging companies' promotional materials on consumers' beliefs about the technology. The surveys showed that $90 \%$ of respondents believed the advertised device was effective in detecting breast cancer, and $80 \%$ believed the advertised device was equally or more effective than a mammogram in detecting breast cancer. ${ }^{5}$ These results prompted CCWA to broaden and intensify its advocacy efforts.

\section{Advocacy}

\section{Legal advocacy}

Three legal avenues for redress in cases of suspected advertising misconduct were identified:

1. Law on the advertising of therapeutic goods

2. Law on the approval, listing and availability of therapeutic goods

3. Consumer protection law.

The Therapeutic Goods Administration (TGA) sits within the Australian Government Department of Health and regulates therapeutic goods in Australia - such as prescription medicines and medical devices - through the Australian Register of Therapeutic Goods (ARTG) and the Therapeutic Goods Advertising Code. CCWA raised a complaint to the TGA's Complaints Resolution Panel (CRP) about a company making unsubstantiated claims about an electrical impedance device. CCWA also submitted incident reports to the TGA in an attempt to reduce the availability of the devices.

CCWA also raised the issue with the Australian Competition and Consumer Commission (ACCC), Australia's consumer law watchdog. CCWA provided the ACCC with information as it conducted formal investigations, including observations on the nature and size of the industry in Western Australia and throughout the country.

\section{Media advocacy}

CCWA engaged with the media to raise awareness of potentially misleading claims. For example, a joint media statement between Cancer Council Australia (a CCWA affiliate), the ACCC and the TGA in June 2011 urged women not to rely on unproven commercial breast imaging technologies to detect breast cancer. ${ }^{3}$

\section{Policy advocacy}

Advocacy was used to highlight government policies that had facilitated the growth of the commercial breast imaging industry and that had failed to ensure adequate oversight of marketing practices. 
A significant limitation of the TGA's CRP is that it has no power to enforce its determinations. CCWA supports stronger powers for the CRP, including the ability to investigate and enforce, and to refer noncompliance to the ACCC, which has powers of enforcement. CCWA made submissions to consultations about the TGA held by the Department of Health and engaged with federal Senators from all major political parties on this issue.

CCWA made a submission in response to the Australian Health Ministers' Advisory Council's consultation paper on a national code of conduct for healthcare workers, including arguing for an enforceable, statutory code of conduct for unregistered healthcare workers - specifically, the inclusion of standard nine: "Health care workers not to misinform their clients". This standard was included in the terms of a National Code of Conduct for healthcare workers endorsed by the Council of Australian Governments' health ministers in April 2015. ${ }^{14}$

\section{Impact}

In response to concerns raised by CCWA, the ACCC commenced legal proceedings against two companies in December 2011, alleging their marketing practices had been misleading or deceptive. At the time, at least 28 companies were offering unproven breast imaging services in Australia. By March 20125:

- Seven of these companies voluntarily ceased trading

- Two added a statement to their websites to clarify that their service was not a replacement for conventional breast imaging modalities

- Three removed the breast imaging material from their websites, effectively ceasing promotion of the service.

In March 2014, the Federal Court of Australia handed down judgements against the companies and their operators. ${ }^{15,16}$ Safe Breast Imaging Pty Ltd (SBI) used an electrical impedance device exclusively, whereas Breast Check Pty Ltd (BC) used various digital thermography devices in addition to electrical impedance scanning. The court found the companies had engaged in misleading and deceptive conduct in their promotional materials. Additionally, SBI had falsely claimed that a medical doctor was involved in the preparation of reports.

$\mathrm{SBI}$, which operated across four Australian states, was fined $\$ 200$ 000, with its sole director receiving a penalty of $\$ 50$ 000. The director was also disqualified from managing a company for 4 years. ${ }^{17} \mathrm{BC}$ 's contraventions were considered less serious and attracted a penalty of $\$ 75$ 000. ${ }^{18}$ The judgements and penalties have been such a strong deterrent that internet search engines for similar companies in Australia now return few results.

Additionally, the TGA removed some thermography and electrical impedance devices from the ARTG, because the companies promoting them were unable to substantiate claims about their ability to detect breast cancer with independent, peer-reviewed literature.
CCWA's complaints to the CRP did not lead to a determination and no further action was taken by the CRP, partly because of their lack of enforcement power.

\section{Discussion}

The marketing of thermography, electrical impedance scanning and elastography directly to consumers is of concern internationally because of a lack of independent, peer-reviewed literature to support the stand-alone use of these devices in breast cancer screening. By adopting a comprehensive legal, media and policy strategy, this campaign was able to contribute to a reduction in the number of Australian companies offering unproven breast imaging devices.

This advocacy was initiated in a climate of intense scientific debate about mammographic breast cancer screening. It has been argued that such programs result in overdiagnosis and overtreatment, and that declines in breast cancer mortality can be ascribed mainly to improved treatments and breast cancer awareness. ${ }^{19}$ Despite its limitations, mammography remains the gold standard for breast cancer screening and is estimated to provide a relative risk reduction for breast cancer mortality of $20 \% .^{20}$

Another challenge was staying apprised of developments in the industry in Western Australia, Australia and overseas. It was observed that websites and social media were the primary means by which unproven breast imaging companies promoted their services $^{5}$, and that the services were often transitory.

There was, and still is, a risk that new unproven devices will fill the gap left in the market after the successful campaign. Although this risk exists, the experience gained, evidence built and partnerships formed during this advocacy campaign will allow for a more rapid, efficient response to any emerging threats.

The mix of skills and organisations among those concerned about the impact of unproven breast cancer screening devices was critical to the success. Each step was guided by a highly experienced public health advocate at CCWA. At all times, however, there was a combination of public health skills and specialised skills relevant to the stage of the campaign. The evidence-gathering activities included experts in market research, health psychology, health technology assessment, breast cancer screening, and breast cancer diagnosis and treatment. The advocacy activities included team members with legal and public health advocacy expertise.

\section{Conclusion}

CCWA's campaign provides a useful case study for public health professionals involved in advocacy and policy development. Like other advocacy case studies, however, it is difficult to draw a causal link between the campaign 
and the outcomes achieved. Because of the nature of advocacy, outcomes lie outside the advocate's control. ${ }^{21}$

Although there is no definitive blueprint for a successful advocacy campaign, there are lessons that can be taken from this work. Although it did not start as a planned campaign, it is consistent with other successful public health advocacy campaigns in that it was iterative, based on sound evidence and drew on a range of advocacy strategies to work towards a desired outcome. ${ }^{21}$

Perhaps the most valuable and unusual aspects of this advocacy campaign were the mix of professional skills involved, the strong partnerships developed, and the strategic collection and use of data during a relatively short period of time. The credibility and authority provided by experts and organisations, combined with the contemporary, relevant evidence used in the early phases of the campaign, is likely to have contributed to its success.

\section{Acknowledgements}

The authors would like to thank BreastScreen WA and Professor Christobel Saunders for lending expertise to this project. We acknowledge the commitment and expertise of Sam Di Scerni and the team at the ACCC. Thanks also to Nicole Shirazee for her work on the early literature review.

\section{Competing interests}

None declared

\section{Author contributions}

TS oversaw the entire project and provided technical input to the manuscript. CK and RJ drafted the manuscript. IP, EC and TV provided specific, technical expertise related to market research, breast screening and health technology, respectively. All authors contributed to the writing and reviewing of the manuscript.

\section{References}

1. Lovett KM, Liang BA. Risks of online advertisement of direct-to-consumer thermography for breast cancer screening. Nat Rev Cancer. 2011;11(12):827-8.

2. FDA. US Food and Drug Administration: protecting and promoting your health. Silver Spring, MD: US Food and Drug Administration. Breast cancer screening -thermography is not an alternative to mammography; 2011 Jun 2 [cited 2015 Apr 10]; [about 4 screens]. Available from: www.fda.gov/medicaldevices/safety/\%20 alertsandnotices/ucm257259.htm
3. Australian Competition and Consumer Commission, Cancer Council Australia, Therapeutic Goods Administration. Canberra: Australian Competition and Consumer Commission. Beware of unproven breast imaging technologies, say ACCC, Cancer Council and TGA. 2011 Jun 11 [cited 2015 Apr 10]; [about 4 screens]. Available from: www.accc.gov.au/media-release/bewareof-unproven-breast-imaging-technologies-say-accccancer-council-and-tga

4. Vreugdenburg TD, Willis CD, Mundy L, Hiller JE. A systematic review of elastography, electrical impedance scanning, and digital infrared thermography for breast cancer screening and diagnosis. Breast Cancer Res Treat. 2013;137(3):665-76.

5. Johnson R, Jalleh G, Pratt IS, Donovan RJ, Lin C, Saunders C, Slevin T. Online advertising by three commercial breast imaging services: message takeout and effectiveness. Breast. 2013;22(5):780-6.

6. Cancer Council Western Australia. Perth: Cancer Council Western Australia. Vision, mission and values; 2016 [cited 2016 Apr 29]; [about 3 screens]. Available from www. cancerwa.asn.au/aboutus/mission/

7. Cenin DR, St John DJB, Ledger MJN, Slevin T, Lansdorp-Vogelaar I. Optimising the expansion of the National Bowel Cancer Screening Program. Med J Aust. 2014;201(8):456-61.

8. National Health and Medical Research Council. NHMRC statement : is there a role for thermography in the early detection of breast cancer? Canberra: NHMRC ; 2012 [cited 2016 Aug 3]. Available from www.nhmrc.gov. au/_files_nhmrc/publications/attachments/s0003_thermal_ imaging.pdf

9. Fitzgerald A, Berentson-Shaw J. Thermography as a screening and diagnostic tool: a systematic review. N Z Med J. 2012;125(1351):80-91.

10. Brennan M, Houssami N. Thermography in breast cancer diagnosis, screening and risk assessment: systematic review. Breast Cancer Manag. 2013;2(2):163-72.

11. Cancer Council Western Australia. Cancer information. Unproven breast imaging technologies - the facts. Perth: Cancer Council Western Australia; 2010 [cited 2015 Apr 10]. Available from: www.cancerwa.asn.au/ resources/2011-4-Unproven-Breast-Imaging-Factsheet. pdf

12. Western Australia Department of Health, Cancer Council Western Australia, BreastScreen WA, The University of Western Australia. Testing for breast cancer: will the real breast screening test please stand up? Perth: Cancer Council WA; 2010 [cited 2016 Aug 3]. Available from: www.cancerwa.asn.au/resources/2010-05-20-breasttechnologies-report.pdf

13. Vreugdenburg TD, Laurence CO, Willis CD, Mundy L, Hiller JE. Content analysis of Australian direct-toconsumer websites for emerging breast cancer imaging devices. Med J Aust. 2014;201(5):289-94. 
14. COAG Health Council. Final report - a national code of conduct for health care workers. Adelaide: Australian Health Ministers' Advisory Council; 2014 [cited 2016 Apr 29]. Available from: www.coaghealthcouncil.gov.au/ Announcements/ArtMID/527/ArticleID/54/Final-Report-ANational-Code-of-Conduct-for-health-care-workers

15. Australian Competition and Consumer Commission v Safe Breast Imaging Pty Ltd [2014] FCA 238 [cited 2016 Apr 29]. Available from: www.judgments.fedcourt.gov.au/ judgments/Judgments/fca/single/2014/2014fca0238

16. Australian Competition and Consumer Commission v Breast Check Pty Ltd [2014] FCA 190 [cited 2016 Aug 3]. Available from: www.judgments.fedcourt.gov.au/ judgments/Judgments/fca/single/2014/2014fca0190

17. Australian Competition and Consumer Commission v Safe Breast Imaging Pty Ltd (No 2) [2014] FCA 998 [cited 2016 Aug 3]. Available from:

www.judgments.fedcourt.gov.au/judgments/Judgments/ fca/single/2014/2014fca0998
18. Australian Competition and Consumer Commission v Breast Check Pty Ltd (No 2) [2014] FCA 1068 [cited 2016 Aug 3]. Available from: www.judgments. fedcourt.gov.au/judgments/Judgments/fca/ single/2014/2014fca1068

19. Jørgensen KJ, Keen JD, Gøtzsche PC. Is mammographic screening justifiable considering its substantial overdiagnosis rate and minor effect on mortality? Radiology. 2011;260(3):621-7.

20. Independent UK Panel on Breast Cancer Screening. The benefits and harms of breast cancer screening: an independent review. Lancet. 2012;380(9855):1778-86.

21. Chapman S. Advocacy in public health: roles and challenges. Int J Epidemiol. 2001;30(6):1226-32.

\section{Copyright: (c) (i) (-)}

(C) 2016 Johnson et al. This article is licensed under the Creative Commons Attribution-NonCommercial-ShareAlike 4.0 International Licence, which allows others to redistribute, adapt and share this work non-commercially provided they attribute the work and any adapted version of it is distributed under the same Creative Commons licence terms. See: www.creativecommons.org/licenses/by-nc-sa/4.0/ 